\title{
A Proposed Program for the Activities of the School Media Literacy in the Development of Some Dimensions of Learning for Students in the Third-Grade Primary Considering the Vision of Egypt 2030.
}

\author{
Dr. Nermeen Singer \\ Department of Media \& Child Culture \\ Faculty of Graduate Studies for Childhood \\ Ain ShamsUniversity, Egypt.
}

\begin{abstract}
Children and youth are living today in a multi-device, multi-platform, multi-channel world, and school children are more affected by different means of media. The current study aims to investigate the effectiveness of the media literacy activities in developing the learning dimensions of the third-grade students in the light of the vision of Egypt 2030? After the application of the study tools on an experimental sample of (40) children in the third-grade primary, the results showed that the use of the activities of the school media literacy to the dimensions of learning in the light of Egypt's vision led to the improvement of the following learning skills "procedural skills and professional skills, Skills of co-existence and cooperation with others. In addition of improving the following sub-skills (Introduce new and unique ideas - problems solving Respect for opinion and other opinion - Define clear goals - Respect diversity - Selfexpression - Verbal communication - Negotiation and good inquiry - Distinguish between similarities and differences).
\end{abstract}

Keywords: Development; Learning; Media Literacy: Vision of Egypt.

\section{Introduction}

Today, children and young people live in a multi-device, multi-platform, multi-channel world. It is widely accepted that knowledge sharing through information technology is a feature of modern societies and an important component of the development of child and student achievement (Fraillon et al., 2014). It has changed the world and made impossible things possible in the world of the twenty-first century, media.

One of the basic assumptions is that the media is a force capable of undermining the social order, social norms and values of society and directly affecting the minds, perspectives, patterns of thinking, and life skills of ordinary individuals, and there may create serious social problems for children and young people worldwide (Baran \& Davis, 2012: 66).

UNESCO (2008) notices that children and young people of school age are more vulnerable or influenced by the media. Regardless of the diversity of contexts surrounding children and young people, they acquire the patterns of behavior, aspirations, and patterns of cultural aspects that the media scene conjures up, and they interact with emotion.

Joshua Meyrowitz (1985) points to the impact of media on children's behavior. Parents can easily learn ways to raise their young children by talking and reading to children only about the things they want for their children. But parents today have to fight with thousands of competing media images and ideas that they do not have direct control over it. "There are a variety of ways that media affect children, which may be long or short-lived.

It is clear - as Lundby wrote, 2009: 2) that traditional and new media, as well as portable means are everywhere, embracing all and cannot be avoided in the modern world.

In light of the saturated nature of modern life, it has been widely recognized that today's children need to develop new media-related competencies that will prepare them to live and participate in the present and future world, change the way we learn about the world and challenge the very foundations of education.

It is no longer enough to be able to read the printed word children, young people and adults also need the ability to interpret critically the powerful images of multimedia culture in a critical way and express themselves in multiple media ways (Avery, 2007; Jenkins, 2008) Recently, integration into the community requires digital skills that have finally come to be understood as vital life skills, along with reading, writing, and arithmetic skills. Both have become a "demand and a right", especially for the exercise of responsible citizenship. 
Digital integration, for example, is no longer a matter of competence, skill, or specialization (Fraillon et al., 2014: 7), but in essence one of the definitions widely accepted that media literacy includes the ability to access, analyze, evaluate, and communicate messages through a variety of formats (Avery, 2007).

Based on this general definition, the National Association for Education the Information Literacy has developed a list of key ideas related to access, analysis, assessment and communication of the media:

0.1 All media messages are "constructive" and are based on each other.

0.2Each media medium has different characteristics, strengths and unique "language" in construction.

0.3 Media messages are produced for specific purposes.

0.4 All media messages contain embedded values and views.

0.5People use their individual skills, beliefs and experiences to build their own meanings of media messages.

0.6The media can influence beliefs, attitudes, values, behaviors, and the democratic process (National Association, 2007).

In Buckingham, 2003, the media is a major industry, generating business or profit-generating tasks, providing us with information about the political process, and ideas, images and representations (realistic and fictional) that inevitably form our view of reality. This literacy is also required to understand life Social development, appreciation and participation.

There is no doubt that in order for the individual to be an active participant in life, modern media should be used. It is often said that the media have taken the place of the family, the church and the school, and this is the greatest social influence in modern society.

Media literacy is based on knowledge, skills and trends in media competency (languages, technology, reception and interaction, production and dissemination, ideology, and finally taste and beauty). This competence has emerged with learning based on "participatory culture, combining the spirit of criticism, On the expression, the development of personality autonomy, the ability to reach a cultural and social understanding, to acquire the skills of acceptance of the other, and not hostility merely when you disagree with him (Ferrés\&Piscitelli, 2012: 75).

Media literacy is an acquired right for children and young people, so it should be adapted to each age group and to each educational level. In education, communication literacy should be gradually linked to abilities, skills or preparations that grow with the child's development, just as with other subjects (language, mathematics, foreign language, etc.) implemented in educational curricula.

Despite efforts to develop media literacy activities, they are receiving resistance from parents, which may be reflected in the school's mission, limited to the information culture, memory in the classroom and the isolation of the school from public life.

At present, the global economic, political, social and developmental variables, which require an open-minded citizen, have the motivation to learn and to be able to think critically about what is presented to him in the media, to sanctify his Arab and Egyptian identity and his urban heritage, and to enjoy the values of belonging to his homeland and progress.

The child must have the skills and abilities to help him to face the future in a positive way, possess diverse information and practice positive habits and values. This is provided by his school media education alongside school education (Fry, 67-69). Access, analyze and judge information, and make children who receive the media think about their usefulness, where children are exposed to sexual exploitation, violence, domination, marketing of unhealthy foods, alcohol and tobacco, unhealthy body images and sex stereotypes. Media consumption affects the behavior of children and can contribute to aggression, violence, domination, depression, obesity, drug abuse and other negative effects on physical and mental health. The most important way to face all these negative effects is to teach our children to look at what they see with the eyes of the intruder (Silverstone, 2004: 442-444).

In the context of the current media landscape, technological innovations are growing at an accelerated pace, media applications are increasing, globalization of culture and economy is being developed, and the media are providing important benefits, including access to information at all times, easy search for information, preservation of social contacts and the creation and exchange of information. At the same time, we need to continually evaluate and choose safe, consistent and manageable media, and judge their quality, because in addition to their benefits, new media also offer potential challenges and risks, such as content and Dangerous media that threaten the security of the community, its serious economic impact, and its potential social and cultural risks (Meeus et al., 2014).

Although media literacy is essential to participation in society, what is the role of education in children's acquisition of this media literacy? What should teachers, professionals and community leaders know to ensure that children become literate learners and media literate? Where learning environments no longer depend on the time of seats in factory-like schools. Learning happens anywhere and anytime. Production happens to any place and time depends on the media literacy. In order to shape the human capital necessary for success and sustainability in a world of information-based duplication, we must invest in the literacy practices of our children and youth. 
In order for children to learn the skills of media literacy, they must learn the difference between fantasy and reality, since many children cannot distinguish between what they imagine and what is real. "Children are innocent by nature and believe what is being said to them, so it takes time to get them to see things critically. Simply by pointing out to defects in ads such as products, places you have tried, and your disappointment, or foods that are advertised as healthy when you know they are not. This will make your child think about the surrounding messages, an important way to start educating children.

As we learn from the surrounding media every day, schools should now turn more than ever before to provide media literacy activities to our students, especially in their early stages. As teachers or media specialists, we can help students understand media messages (television, newspapers, the Internet, radio, etc.) better by engaging students in a variety of school media activities that help them understand the role of the media by providing them with enlightening life, work and citizenship skills in the century Twenty-one.

In addition, this paves the way for learning, acquiring and developing the skills required for lifelong learning in an everchanging world and moving efficiently through today's society (Farahati, 2009). It is no longer enough to teach reading ability, In a critical manner.

Media literacy is a preventive approach that makes children as a "most sensitive group" of media influence. They need to raise their media awareness through school media activities that make them evaluate the potential harmful impact of media texts. Child protection or self-prevention of the potentially harmful effects of the media (Livingstone \&Bovill, 1999; Livingstone \&Bober, 2004)

Media literacy is linked to skills similar to the dimensions of learning including:

0.7 Critical thinking about information messages received by students

0.8 The media literacy is more than literacy of reading, writing and counting to include all forms and media.

0.9Media literacy builds students' life skills. Therefore, the media literacy activities in the school should be presented in order to make an effective impact on the pupils' personalities and help them acquire experiences and knowledge that contribute to their successful adaptation to multiple life situations (Potter \&December, 2010: 678).

Perhaps the time has come to overcome our fears of "proving" that the media is standing against the formation of the students' personality in the school. Perhaps we should ask, what is the actual or potential relationship between the media activities in the school and the formation of the students' personality and their achievement of the dimensions of the new learning? Can we create a strong and persuasive influence on media literacy activities in achieving the dimensions of modern learning and the formation of an integrated personality?

The research and studies of the importance of educational activities in different educational stages have been studied in many studies (Friesem, 2013, Neag, 2015). The teachers can teach the media literacy to children and students using specific subjects such as arts and music (Reading and understanding of many types of texts); in the lessons of history, geography, and science, which provide possibilities for enhancing media literacy, all of which make learners explore, analyze and present Wen information.

The study of Laila Rashad and Alia Yahya (2009), which focused on the activities of the printed media in the books of civic education, and visual information in the books of national education for the fifth, sixth and seventh grades And the study of Fayza Mohammed (2007), which recommended the creation of specialized media on education issues by qualified individuals, and the establishment of a committee of educators and media professionals to plan a media literacy program that protects children from the dangers of the media and makes them think critically.

One of the most important aspects to be addressed by a student in the first grade is learning, including aspects of national awareness, life skills, global issues and challenges. Learning to learn (vocational skills) Learn to be (self-skills) learning to live (skills of cohabitation) The previous issues are of great importance since childhood. It works to instill appropriate attitudes for students from their young age to train them to be able to learn for life and global competition. There are several roles that these activities play in the education process, as well as its role in supporting the values, customs and traditions of society. It has a major role in the development of thinking skills (such as critical thinking and problem solving (Ministry of Education, 2011: 4-6)

The information explosion was a major challenge to formal education. It is designed to ensure that students know the facts around the world by correctly answering test questions. But such a system is no longer appropriate when the most recent facts are available by the touch of a button. What children need today is to learn how to search for what they need to know when they need to know, and to acquire higher thinking skills to analyze and evaluate whether the information they find is useful for what they want to know. 
How will schools do this? First, schools and classrooms must be transformed from being a storehouse of knowledge into a portable tent that provides shelter and a place for students to gather while exploring, questioning, experimenting, or discovering! Second: Using the sentence of the Brazilian teacher "Paulo Freire which is "Education must be distinguished from "banking" and it is no longer necessary for teachers to pump information into the heads of students. The wise teachers realize that they do not have to be "wise on stage" and instead their role is to be "an important encouraging side guide, an engine and a facilitator" for the learning process. And that the creative classrooms today are those where everyone learns, including the teacher! Third: Design lessons and activities that will integrate students in solving problems. The multimedia culture today, especially the school media literacy activities, provides an unlimited resource for understanding the real world - from a "point of view" and exploring how camera angles affect our perception of the subject being film, and determine whether information on a website is false or true (Zhang \& Zhu, 2014).

The transformation of our culture from the age of industry to the information age has contributed to a new kind of media literacy in the 21st century. Because most of what we call formal education in schools is linked to what we type or put in the human mind from the information we may need for life. This information-oriented education is neither possible nor necessary at present. Rather, humanity needs to learn to process information stored through media technology and media literacy. And that education should tend to data processing than data accumulation "

The activities of the media literacy in the school as programs complement the school social function, where these activities contribute to the exercise of self-expression and satisfaction of the basic needs of students, along with the development of citizenship, decision-making, respect for opinion, self-management and participation.

It is possible that these activities in the first grades of the primary stage will have an effective role in developing their national awareness and instilling positive attitudes toward future participation in society. This depends on the preparation and use of these activities to suit their specific objectives (Ministry of Education, 2016) and this provides the opportunity to achieve effective learning by satisfying the students' tendencies and freeing their ideas and makes them satisfied with what they are doing; that the children will have a better future and contribute to their country's progress in the near future (Ministry of Education 2018: Egypt's vision 2030).

Consistent with this vision, previous researches have been conducted on the role, importance and objectives of school media activities. The most important of which are: satisfying students' interests, developing skills and values of life, respecting individual differences among learners and solving the problems they face in life (Darriya El Sayed, 2004; Essam Amar 2008)

As the activities of the media literacy in school to develop the personalities of students and help them to grow, progress and acquire expertise and skills to help them to cope with different life situations, and also considering that the attention to national awareness, especially at this stage of the necessary things at the moment in the Egyptian society that tend to consolidate values, Life skills, and the promotion of diverse values in its way towards a free open economy.

Based on the above, the need for the field to establish a vision for the development of school media literacy activities based on the "vision of Egypt 2030" and study its effectiveness in the development of learning dimensions of students in the third grade in the light of the vision of Egypt 2030.

\section{Mythology}

\subsection{Research problem}

The need for harmony between education and the media is urgent, and it assures that media literacy contributes to the graduation of students who can play their part in an age of information flow so that they cannot be a prey to malicious claims and misleading propaganda.

Egypt has witnessed a remarkable growth in education. The Ministry of Education has adopted a new vision, the most important of which is the provision of learning opportunities that enrich students' experiences, develop their independence, and contribute to building a generation capable of taking responsibility, making decisions and achieving comprehensive development in their societies.

Despite the scarcity of studies that dealt with the literacy of the school media regarding the development of the different dimensions of education in the light of the vision of Egypt (2030) and confirmed some of the hypothesis of this research, the most important of which are: AsmaaElsedik (2014), which focused on developing a concept to disseminate the concepts of media education and its defects. And that the concept of media education " media literacy" doesn't exist in schools. And the lack of training of media specialists on the concepts of "media literacy" and the study of Maha Abdel-Fattah (2012) confirmed that some media messages contribute to the promotion of Western culture and philosophy in life. And that the advantages of media education that it helps students to think critically and access to the truth, and the consolidation of cultural identity and national affiliation. 
And the study of Samih Abdul Hakim (2010) that pointed to the importance of providing students with some of the concepts of the media and helping them in the development of different criticism areas the study concluded that the media education with the choice of the appropriate method of education contribute to the upgrading of students.

The study of Fayza Mohammed (2007) showed the need for cooperation between education and media for development and recommended the creation of specialized media in educational cases by qualified individuals. And the study of Muhammad al-Khatib (2007), which confirmed that media education provides many suitable opportunities to address the psychological, cultural and social problems suffered by students in school such as the problem of illiteracy of civilization, technological illiteracy and political illiteracy as well as tensions arising from communicating with others, .... etc. Therefore, it is necessary to pay attention to school media literacy activities as an input to the development of thinking skills and learning dimensions. The problem of research can therefore be framed in a report entitled "The lack of school media literacy activities in the development of the learning dimensions of third-grade pupils in primary school". This problem can be solved by answering the main question: What is the effectiveness of a proposed program for media literacy activities in the development of learning dimensions in the third-grade students in the light of the vision of Egypt 2030?

The following questions are derived from this:

-What are the skills of media literacy activities related to Egypt's vision in education 2030, suitable for third grade pupils?

-What is the appropriate program of media literacy activities to develop some of the education dimensions of the thirdgrade pupils?

-How effective are school media activities in developing some of the education dimensions of third grade pupils?

1.2. Research Objectives:

The current research aims to:

1.2.1 Preparation of a program in the activities of media literacy.

1.2.2 Preparing a list of media literacy skills related to Egypt's vision in Education 2030, suitable for third grade students.

1.2.3 Studying the effectiveness of the proposed model in the development of some dimensions of education for students in primary three in light of Egypt's vision in education 2030.

1.3. Research Importance

1.3.1 This research may contribute to the development of media literacy skills for teachers of educational activities in general and school media in particular with the educational stages to develop programs of educational activities.

1.3.2 A platform for research and other studies adopting strategies based on school media literacy activities.

1.3.3 The possibility of benefiting from the testing of media literacy activities in the preparation of similar tools in other areas.

1.3.4 In a media culture, learners need to be trained in critical thinking and self-expression. The school media literacy forms and develops these basic skills, making them citizens understand and realize public discourse, contribute to it, and finally take appropriate decisions when exercising voting.

1.3.5 The high rate of consumption of the media. The child is exposed in the school to various media such as: video games, television, pop music, radio, newspapers, magazines, billboards and Internet! Compared to previous generations. And that training children in educational institutions on media activities gives them the skills they need to navigate safely through this sea of images and media messages throughout their lives in the future.

1.4. Research Methodology

The researcher used the Descriptive Research method to extrapolate previous researches and build research tools and the program of media literacy activities and the Experimental Research in the application and training of the proposed program.

1.5. Research hypotheses

1.5.1 There are statistically significant variations between the mean scores of the sample in the tribal and remote applications of the media literacy skills related to the dimensions of education.

1.5.2 There are statistically significant variations between the mean scores of the sample in the pre and post applications of media literacy skills related to the dimensions of education in favor of the post application.

1.5.3 The program is characterized by an appropriate degree of effectiveness in the development of school media literacy skills related to the dimensions of education.

1.6. Research Terminologies:

1.6.1 The activities of the school media literacy 
The activity is an activity organized by the school and discharged by children according to their abilities and desires and satisfy their needs to achieve a clear goal for the child such as achieving some goals of education mentioned in the vision of education for Egypt 2030.

The activities of the media literacy are appropriate media activities (radio, school press, radio, written newspaper, electronic newspaper, cartoon, simulation of parliament in school, television and social media websites) practiced by the child in order to solve or confront academic and life issues that link him to the global and local reality and give him a variety of skills such as: differentiation between the similarities and odds, new ideas, determining clear goals, social and personal self-expression, critical thinking skills, and solutions to various life problems

\subsubsection{Education dimensions}

Is a set of dimensions that are based on learning for knowledge and work, coexistence and communication, and selfmanagement and expression. It is programmed in various activities and projects prepared by students in the first grades of primary school such as magazines, poster design, brochures, radio and newspaper interviews.

1.6.3 Pupils of the first grades

Primary school pupils in the first grades of primary school from primary one to primary three.

1.6.4 Egypt Vision 2030

A balanced and diversified competitive economy based on knowledge and innovation, justice, integration and community participation, and a cooperative and diversified ecosystem that invests in innovation to achieve sustainable development and improves the quality of life of the Egyptians (Sustainable Development Strategy, 2015, 13). Therefore, Egypt vision in Education (2030-2014) is a vision that focuses on global local issues and challenges and the programming of the previous public vision.

1.7. Research steps

To answer the research questions, the researcher took the following actions:

1.7.1 Review previous research's, studies and literature in school media activities and media literacy activities in particular.

1.7.2 Deriving a list of the skills of the activities of the school media literacy related to the dimensions of education in the light of Egypt's vision in education 2030 .. and to ensure its sincerity and stability.

1.7.3 Building a brochure for the activities of the school media literacy activities related to the dimensions of education.

1.7.4 Building the proposed program.

1.7.5 Selection of a sample of students in the third-grade primary.

1.7.6 Teaching the proposed program for the research sample.

1.7.7 Interpreting the results and make recommendations and proposals.

\section{Theoretical framework and previous studies}

\subsection{School information activities}

Activity of Educational performance practiced by children and express their tendencies, needs, and learn through which skills are difficult to learn in the classroom, such as working in a team and take responsibility, and self-control, and respect for manual work.

The activities of an educational institution are geared towards children in accordance with their needs, their abilities, their full needs for performance and their psychological and social existence. Scheibe \& Rogow, 2012: 45-46).

\subsection{The media literacy school}

Media literacy is the critical understanding of what the media broadcast and what is produced in the media through the exercise of information literacy activities. The ability to access, evaluate media messages, and conduct media activities gradually, media literacy is linked to good school practices in society and society (Neag, 2015)

A group of UNESCO experts provides a list of important terms such as: media literacy, information literacy, library literacy, news literacy, computer literacy, web literacy, theatrical literacy, theatrical literacy, television and advertising, etc. Many of these terms remain the subject of discussions (UNESCO 2011: 19) The information and information literacy seeks to identify three main interrelated areas under which the media literacy

2.2.1 Knowledge and understanding of media information for democracy, politics and social participation

2.2.2 Evaluation of information texts and information sources

2.2.3 Production and use of media and information

This outlines the skills, knowledge and social activities of children in school and in the classroom, making students active participants in their learning process, self-affirmation, self-esteem, and the development of their school and community. 
This global movement in the media literacy has generated three national organizations in the United States that offer training in information literacy, communication and information. 1 - Center for Media Literacy 2 - National Association for Media Literacy - Coalition for Media Education (Hobbs \& Moore, 2013)

The UNESCO Conference on Media Education, held in Vienna in 1999, stressed that media literacy is a fundamental right of every citizen of any country in the world of freedom of expression and the right to information, a tool for building and maintaining democracy. And that media education should aim to empower all citizens in every society, including people with special needs, and socially and economically disadvantaged, Silverblatt (2001) presents a more comprehensive definition of media literacy, including:

2.2.4 Critical thinking skills that allow children and students to develop independent judgments about media content

2.2.5 Understand the process of transferring or exchanging information widely to a wide range of individuals

2.2.6 Develop strategies to discuss and analyze media messages

2.2.7 Be aware of the impact of the media on the individual and society

2.2.8 Awareness of media content as a text that provides an insight into our contemporary culture and ourselves

2.2.9 To promote increased enjoyment, understanding and appreciation of the content of the media

2.2.10 In the case of communication with the media, the ability to produce effective and responsible information messages.

Media literacy typically includes the competencies of understanding, understanding, analyzing, and evaluating media messages, making media messages publicly shared with others, and hoping that the contents of current media messages (Hobbs \& Moore, 2013).

Potter $(1998,2013)$ refers to media literacy because it is based on a developmental perspective. According to this concept, children between the ages of 3-5 develop the so-called "rudimentary skills" for informational literacy and that children between 5-9 years begin to develop critical assessment skills, which become more important In adolescence and puberty, when "advanced skills" are acquired, the primary skills are linked to the basic ability to read media symbols and to identify the patterns that these symbols create, and to give meaning to those patterns. (Potter, 2013)

2.3 The dimensions of the media literacy in the first stages.

The dimensions focused on the media literacy of children in the early stages are:

2.3.1 The Language Dimension, which revolves around the rules and the use of the laws of audio-visual communication or analysis of messages and there are four indicators for that:

2.3.1.1 The ability to interpret and evaluate message symbols. Children may understand less about the elements of the audiovisual language, but specific elements such as music or footage can allow a child to understand their meaning and choose it visually and visually.

2.3.1.2 The ability to analyze and evaluate messages from the perspective of meaning, and then move away from developmental and cognitive constraints in children between the ages of 3-6 years, which contribute to the children's lack of understanding of the audio-visual message. It must be recognized that a good audiovisual product must be selected by the teacher in time for the child's maturity and ability to understand and evaluate what is presented to him 2.3.1.3 The ability to understand the flow of stories and information from media, networks, and platforms At this stage, the child begins to understand the sequence and place of the story, especially considering the production of transmedia that can meet the child's needs

2.3.1.4 The ability to create links between texts, and produce an open knowledge. It is easy for a child to fully imagine the universe created by his favorite series by hearing only his songs (sounds). The same thing happens with anecdotes or video games that help create this relationship.

\subsubsection{The Area of Expression Dimension considers the following indicators:}

2.3.2.1 Self-expression through representation systems: Communication does not depend only on language but other systems, such as the image. At this stage the child must be able to communicate with the audiovisual language.

2.3.2.2 The ability to choose between different representation systems: At these ages, children are able to change the language that is seen according to the situation find themselves and talk to them. A symbolic game can help work with it, where the child is placed in a communication environment and transformed into unique characters. If we listen to a football match, the children will tell the story of the game. They can then "reinterpret themselves based on the content and the selected moment.

2.3.2.3 The child can modify simple visual texts which he sees, or a story he heard

2.3.3 Technology Dimension:

This dimension depends on the use of various technological tools. There is no doubt that the technological capabilities of children of this age seem low, so that they can only interact with modes that enable the child to expand their thinking skills and interact with multiple screens that can be learned in their medias (television, computer, smartphone, tablet, ...) 


\subsubsection{Reception and Interaction Dimension:}

2.3.4.1 The ability to discern why certain media, products, or content are loved and satisfied by the senses and emotions of children and raises the cognitive, aesthetic, cultural, and so on. All these aspects, which are related to important desires and aspirations, as children have identified tastes and can explain why. This ability to discuss can be addressed after watching a children's animated program or a short film, either verbally (group of questions / answers) or even through more manual activities.

2.3.4.2 Assess the cognitive effects of emotions: Understanding the ideas and values associated with personalities, actions and situations that generate positive and negative emotions according to the situation in question: Audiovisual media are windows for real or imagined stories. Feelings and emotions are an indispensable resource for showing the emotional state of characters when confronted with events that occur from During the audiovisual narrative. This results in the future feeling more or less empathetic towards a particular person, his actions and the manner in which conflicts are resolved, In the early stages of education, we can play a role in recognizing emotions, and taking advantage of the expression of faces that characters show in animated children's shows. In this way, we can call the child to think about a specific emotional reaction to the personality, and its connection to a situation similar to the daily life of the child.

2.3.4.3 Express the perception of the importance of context in the interactive processes of reception and interaction. At present, there is a possibility for contexts that lead to receiving a specific message of a different nature, thanks to the multiple current screens. Multimodal communication, or transmedia studies show diversity and societies adapt its product. This has led to media that enhances individual reception (computer, tablet or smartphone) and other media intended for consumption in mass reception (computer or television). This allows sharing the actual space used in the reception (home, chapter, film theater) with the context where the stories are developed on screen, Share emotions and feelings with a friend nearby, or even share the experience of viewing with people we do not know (cinematography), but become a group or unity through the magic of cinema when the presentation of the audiovisual narratives together. These aspects can be handled with the smallest. Let's think for a moment about the basic rules of conduct when we go to the cinema, which allows coexistence with the rest in the same place and without conflicts, which promotes good reception.

2.3.4.4 Appreciate messages from other cultures, to intercultural dialogue in the media age without limits. Tolerance and respect for other beliefs, solidarity or curiosity about cultural diversity are values that must be instilled from an early age. The teacher must find documents that illustrate the characteristics of other cultures for their knowledge and respect.

2.3.5 Production and Diffusion Dimension:

Using technological resources and we can adapt and take into account three indicators:

2.3.5.1 Knowledge of the basic differences between individual and collective production, and between popular and institutional production; in the case of the latter, between production by citizens and private entities. The child may not be able to distinguish between each type of production because of its age, but we can begin to practice the difference between individual and collective production, These aspects can be implemented in the first stages of education through two simple examples: Students aged 3 to 6 years can take a picture of themselves, and can be considered an individual (non-professional) image, because they do not need more people to be produced. However, if we consider other types of audio-visual products (animation, radio, television, movies, sports programs ...), We can say that there is a need for a working group (journalists, screenwriters, lighting specialists, photographers, actors, directors, broadcasters, producers ...), which require cooperation and task assignment; This basic distinction can be initiated from the early years of study.

2.3.5.2 The ability to work collectively in the production of multimedia or multimedia products. At this school stage, teamwork and cooperation are very important for stimulating the essential aspects of co-existence in society. It is known that the media are characterized by collective action, In the field of education, as in the creation of media products, there is a need for collaboration among all relevant agents to move forward with projects that improve teaching / learning processes. These children should learn to participate, and they should begin to recognize that there are processes in which cooperation with others is needed to make them work (creating a radio story in which each child has a different role and participation is important). The teacher will be responsible for publishing the programs through podcast or school radio.

2.3.5.3 The ability to select meaningful messages, use them and convert them into new meanings. If you think about animated shows or movies, the child tends to retain the basic parts, the parts they like most, or anything that interests him. Perhaps he will not be able to remember the entire audio-visual plot (especially if the structure is non-linear), but he is able to reproduce new stories and endings with new characters. At this age, the child acts by tradition, and because of this, he can easily reproduce what appears in the screens when he plays, allowing the screens to become part of his reality with this transformation. 


\subsubsection{Ideology and Values Dimension:}

Comprehensive and critical reading of audiovisual messages in addition to the values that represent this reality. This is associated with five:

2.3.6.1 The ability to discover how the media portray the reality. Let's think about how to make your ad address a specific product, with a specific brand ... just like in their favorite shows. The fact that children tend to imitate this age has already been mentioned: they feel familiar with the character, the way they act, and think of themselves as superheroes, princesses, pop stars, etc., unable to distinguish reality from reality. Training is therefore indispensable in imagining what is real or imaginary at these ages, and it is important to help the child understand this distinction.

2.3.6.2 The ability to manage our emotional responses when interacting with screens, according to the ideology and values evoked by these screens. Audiovisual messages evoke feelings, a sense of being, and we can even make us feel the emotions of a particular personality. Children's screens make people laugh, cry or feel happy, and feelings that the child must first identify for mastery or management.

2.3.7 The aesthetical dimension of audio-visual messages, this dimension includes the following:

2.3.7.1 The ability to enjoy the formalities of the media, not only what is connected but the form of its connection and there are principles governing aesthetic taste and we can even with time, they evolved (architecture, painting, illustration, sculpture ...) In the audiovisual field we should think about Colors associated with emotional states, feelings ... through aesthetically taught in terms of form, print, or image quality.

2.3.7.2 Allergy to identify media texts that do not meet aesthetic requirements: The aesthetics of modern animation vary greatly from the eighties and nineties of the last century, which is why many of them have been redeveloped to achieve aesthetic results more attractive like modern products.

2.3.7.3 The ability to link media production with other technical outputs and to detect mutual influences: This indicator can easily be worked on at this stage, as there are many audiovisual products based on specific historical periods or personal personalities. Through her presentation, the child will be able to create a relationship with other artistic aspects

2.3.7.4 The ability to produce initial messages that can be understood and help to raise the level of personal or collective creativity and originality. The production of radio messages by the child is applicable at these ages. Telling stories, telling weekend events, or how they feel, etc., can be a great way to work on this ability, at the same time as we work with verbal language ordering ideas and choosing enough words to express an idea,enhance the creativity, experimentation and aesthetic sensitivity of the child. The child is able to reproduce the work. In this way we can play by copying pictures from their favorite films, giving them the freedom to modify and introduce elements without ignoring the aesthetic principles of the image (Mueller, Wood, Willoughby, Ross \& Specht, 2008; Rodriguez-Rossel, m \& Moreno, $\mathrm{m}, \mathrm{I}$ 2016).

2.3.7.5 Literacy depends on various factors, some local, some global, and if we want to define the concept of literacy and its elements, to be an influential factor, it needs to be searched and compiled from several sources: the problems of society, which is one of the important pillars in the formation of the culture of individuals. Global trends and through school media including school press, lectures, seminars, school radio, summary, newspaper article, wall magazine, volleyball magazine, brochures and electronic article, social networking sites, television , Goodman, 2003) and the development of children's physical and mental abilities, which will help them in the future to choose the type of profession suitable for them, in addition to deepening belonging and raising the capacity of criticism and creativity, good behavior in different situations and ability To taste and contribute to problem solving (Grant, 2004).

2.4 The importance of Media literacy:

There is no doubt that the media literacy of the students in the first grades is positive by practicing these activities:

2.4.1 In media literacy culture, individuals need two skills to integrate into society: critical thinking and selfexpression. The media literacy instills these skills from the first grades, which trains children to practice democracy in the future through political mobilization, understanding and contributing to public discourse, and ultimately making informed decisions during voting.

2.4.2 The high rate of consumption of the media and the saturation of the community media messages. When one looks at video games, television, pop, radio, newspapers, magazines, billboards, internet - even t-shirts! We are exposed to more moderate messages in one day than our older ancestors have in one year. Media literacy gives children the skills they need to navigate safely through this sea of images and messages throughout their lives.

2.4.3 The influence of the media on the formation of concepts, beliefs and attitudes. While research does not agree on the extent and type of impact, media experiences have a significant impact on how we understand and interpret our world. By helping us understand these influences, school media can help us break away from our dependence on them. For example, media literacy gives children the ability to confront rather than surrender to media exposure, isolation or rejection simply to reject or merely justify issues and matters. 
2.4.4 Increasing importance of visual communication and information. While printing is still applied to schools, our lives are increasingly influenced by visual images - from corporate logos to building-size billboards to websites. Learning how to "read" multiple images-based communications is an important element of traditional media literacy. We live in a multimedia world.

2.4.5 The importance of information in society and the need for lifelong learning. Information and information processing services are at the core of our country's productivity, but the growth of the global media industries also challenges independent voices and diverse opinions. Media literacy can help both teachers and students understand the source of information that may be presented in their interests, how to find alternative perspectives, help them interpret and understand things, and acquire analytical skills and capabilities.

2.4.6 To help them understand their positions when others, whether those at home or abroad, so the school media education is thus a fundamental way to become the concepts that acquire the factors of division and difference and differentiation Almthmum and impressionist images and counter images.

2.4.7 To help children to understand their rights and duties and the rights and duties of others as well as to understand many of the prevailing concepts such as the concept of Shura versus democracy and the concept of human rights and the concept of women's rights and the concept of freedom and the concept of minorities and the concept of privacy and others.

2.4.8 To deepen the sense of belonging and develop the abilities of students to innovate and creativity, good behavior in different situations and the ability to taste and contribute to solving environmental problems surrounding and interact with them. And the discovery of leaders of students and help them to carry out their responsibilities in accordance with the concepts of philosophy of education.

2.4.9 When children grow up and become able to distinguish the fantasy world from the real world they live in, they can explore how to put the media together by turning off the sound during a cartoon and pointing out the difference it is making, or even creating their own story using a home video camera and easy to use, And edit programs on the family computer. When students start using the Internet to search for school projects, they can compare different websites and different versions of the same information to discover political bias or "spin." The question-asking process is usually applied to the selected media "text" ie a select production or publication, or part of one: an episode of Power Puff Girls, a Pepsi advertisement, a magazine version, a headboard, photos and articles about bank robbery in the foreground Page of the newspaper, broadcast a new hot video game.

2.4.10 The media literacy of children contributes to the positive recruitment of children's energy by providing opportunities for communication, self-expression and participation. The media are exposed to cases of intimidation, harassment and even suicide. Prompting parents, educators, media professionals and media professionals to try to develop children's media awareness from a young age and manage online interactions to reduce the risk of harm. It may seem a clear goal to maximize access to the Internet while minimizing the risk of damage, To achieve this goal, researchers and policy makers have sought to improve children's digital skills. But after safety campaigns and awareness-raising, children learn more easily messages (such as not talking to strangers or not disclosing personal information) from changing their behavior

Such ambiguity helps to explain why research has found that children's online opportunities and risks are positively linked - the more opportunities they have, the greater their risk exposure and vice versa (Livingstone 2008; boyd, 2014).

What is more dangerous is that multi - media institutions establish the basis for the exchange of images and information that affect the beliefs and behavior of the viewers and their trends. (Rizk 2016; Asma al-Siddiq, 2014, Ruwaini. In the age of information explosion, the school must enlighten its students about what is acceptable and what is not acceptable in the continuous information they receive. The only way to provide students with skills to enable them to investigate the media information and to inform them to make informed decisions about them It is important to consider literacy as a constructive interactive process of media literacy, which builds the personality of the child and enables him to develop critical thinking skills and empathy, which leads to a sense of self-efficacy, identity and full participation in society, encourages social interactions and develops the habits of the productive mind (Brunner \& Tally, 1999) and positive attitudes towards learning and a learning environment (Luckin, 2008).

One of the most important strategies of the media activities is to prepare students to deal consciously with the media, develop critical thinking skills among students and create media awareness so that the student can be a positive recipient of the media messages analyzed and conducted and even co-written in an interactive manner. Some educational systems, especially the Western ones, In media education to make students able to consciously address this media flood that is besieging them everywhere and we are still two dimensions from this field (Al-Saghir, 2012; Abdelhamid, 2009, Othman, 2006). One media specialist knows that media education is the ability to read, analyze, 
evaluate and produce communication. Media awareness is not limited to receiving and criticism, but must be addressed to conscious and meaningful participation in the production of media content.

However, media education includes the ability to communicate information and ability to Analyzing, communicating, and communicating messages. He also emphasizes that by teaching students how to evaluate the media images that surround them, we provide them with the means to make responsible choices about what they hear and see.

\section{Study Procedures}

\subsubsection{Study tools:}

The activities of the educational media literacy for the dimensions of learning and vision of Egypt 2030

The educational activities of the school can be visualized through its findings as follows:

3.0.1.1 Scientific skills include: Distinguish between similarities and differences - Introducing new and unique ideas Suggest solutions to problems.

3.0.1.2 Professional skills include: - Respect for opinion - the establishment of clear objectives.

3.0.1.3 skills of coexistence - knowledge of roles - respect for diversity.

3.0.1.4 Self skills include - self-expression - verbal communication.

For example, Livingstone (2008) pointed to the need to focus on the dimensions most appropriate to the developmental needs of pupils, especially training them to cope with media risks and to sanctify their privacy while communicating electronically. And to have the cash capabilities of the media messages, and this contributes to the development of life skills.

The researcher relied on the sources of the program to build the program (previous research on school media literacy and programs based on the teaching of school media education - the literature of the school media and the dimensions of learning and vision of Egypt 2030 in education.

The program included, theoretically, ten (10) activities dealing with school media activities, and practical aspects of practical applications through activities designed for this purpose. The content of the program is considered to be suitable for the level of students, covering the dimensions of learning according to the vision of Egypt 2030, and to adopt the strategy of presentation on discussion, dialogue, brainstorming and presentations using Power Point.

In this study, the development of learning dimensions was based on the urgent need to solve the real problems faced by students in living with real life and communicating with them and making appropriate decisions. In order to be effectively developed, - Available capabilities - Performance evaluation - Take appropriate and appropriate decisionmaking actions, provide self-guidance opportunities through questions, and thus promote self-evaluation.

The researcher prepared a guide for activities, in which she presented a range of activities that the teacher can choose from, which fits the needs of students and the dimensions of learning. These activities provide opportunities to interact freely with the media and achieve the learning dimensions. Through the following actions:

3.0.1.5 Activity begins by identifying learning outcomes to be achieved through activity.

3.0.1.6 Provide a brief idea of the activity to help the teacher to deal with the activity.

3.0.1.7 Identify the tools to implement the activity, and then the educational materials served by the activity.

3.0.1.8 Procedural steps to walk in the activity is individual or collective, and so on.

3.0.1.9 Evaluation and interested in giving models of assessment of the teacher on the activity.

3.0.1.10 The role of students is to participate. And to identify their role and responsibilities. And to familiarize them with the roles and responsibilities of others, self-reliance in the framework of cooperative learning, and the acceptance of student's activities that suit their interests, interests, abilities and readiness.

3.0.1.11 As it is not possible for any program to develop all the skills of appropriate learning dimensions for a particular stage, some of these skills should be chosen. The skills of learning dimensions in the light of Egypt 2030 vision included the relative importance of each skill.

3.0.1.12 Test the literacy of the school media related to the dimensions of learning

3.0.1.13 The researcher prepared the test of the school media literacy related to the dimensions of learning according to the following steps:

3.0.1.14 Measuring the existence of information literacy related to the dimensions of learning among students in the third grade primary. In formulating the test vocabulary, the researcher considered the following:

3.0.1.15 Examination of many tests meant to measure the literacy media

3.0.1.16 Dependence on objective questions, multiple alternatives to answer questions, and suitable for language installation of students at this age.

3.0.1.17 Distribution of the correct answer among other alternatives in an irregular way to minimize the impact of the guesswork.

3.0.1.18 Avoid words that suggest the correct answer such as: (always, constantly, usually ...). 


\subsubsection{Test Instructions:}

The researcher took care that the test instructions are clear and do not rely on crooked methods. The test instructions included the following:

3.0.2.1 Listen to the teacher when reading the text.

3.0.2.2 Think carefully before answering.

3.0.2.3 Choose one of the three alternatives.

3.0.2.4 Do not place any mark in the booklet of questions.

3.0.2.5 Mark ( $\square$ ) in front of the correct answer among three alternatives, and the researcher developed an example that shows how to answer the questions.

Prepare a perforated key to correct the answers to the school informational questions related to the learning dimensions and set the scoring system on a one-degree basis for the correct answer and zero for the wrong answer.

3.0.3 Initial test image:

The initial image of the test (35) included a single type of multiple choice to measure the school media literacy related to the learning dimensions of the third grade pupils.

3.0.4 Validation of the test:

The test is honest if it measures what is supposed to be measured and nothing else. The researcher used the "content validation" by presenting the test in its initial form to arbitrators specialized in educational media and child rearing in order to determine its suitability to achieve the goal set for it.

The preliminary picture of the test included a presentation of his goal. The arbitrators were asked to give their views on the correctness and clarity of the test instructions. Each question is suitable for the measurement, validity and adequacy of the alternatives listed under each question. And suitable for test vocabulary for the students.

This step resulted in the arbitrators making important proposals such as: to amend some questions to further clarify their meaning, and to rephrase some paragraphs, and the researcher conducted these observations.

The rate of agreement among the arbitrators on the test vocabulary ranged from $(72.2 \%-94.4 \%)$ for each individual item, while the percentage of agreement on the test as a whole was (82.8\%). Which means that the test is honest, and already measures what the setting is to measure.

\subsubsection{Experimental Test:}

The test was applied to thirty (30) students and students from the third grade of primary school in order to ensure the understanding and clarity of the test instructions and analysis of test vocabulary. The exploratory experiment resulted in the following:

The clarity of the test instructions: The researcher made sure the clarity of the test instructions for the majority of students, where the questions were not many, not repeated, has not been modified.

3.0.6 Calculation coefficient of ease per item:

The ease of any test vocabulary is measured by calculating the arithmetic mean of the correct answers. The values of calculated ease coefficients for the test vocabulary ranged in the statistically acceptable range $(0.2-0.8)$.

3.0.7 Calculate the discrimination coefficients for each item:

The coefficient of discrimination is the ability of the individual to distinguish between students with high and low performance. In order to calculate the coefficient of discrimination, the grades of the sample of the survey sample were arranged in descending order, and were divided into two groups, the first being the highest (27\%) and the number of approximately 10 students with high performance. The second is the lowest (27\%) of low performers. The researcher used the equation to calculate the ability of each individual to distinguish:

It was then possible to ascertain the coefficient of discrimination of the test vocabulary and accept it statistically. The individual receiving (0.2) or more can be accepted. Those with a coefficient of less than 0.2 cannot be accepted.

\subsubsection{Stability of the test}

Firmly the test reveals high consistency in test results. The test is fixed if it gives the same results or approximates if repeated to the students themselves and under the same circumstances In order to determine the stability of the test, the researcher applied the method of re-application. It applied it to a survey sample and was re-applied after three weeks. The coefficient of correlation between the two applications was calculated. The correlation coefficient between the two applications was $0.82 \%(0.74 \%)$. This means that the coefficient of test stability $(74 \%)$ is an appropriate value indicating its stability.

\subsubsection{Calculate test time}

The test time is calculated by calculating the average time taken by students to solve the whole test vocabulary. On average, students took 25 minutes to answer questions:

Total test time $=25$ minutes $\square 5$ minutes to write personal data $=30$ minutes

In the light of the results of honesty, ease, discrimination, consistency and test time, the final test is valid for the application to measure students' performance in the school information curve related to learning dimensions. 


\subsubsection{Final test image:}

The number of the vocabulary of each of the test after the previous modifications (30) single, and table (1) shows the specifications of the test of the media literacy school related to the dimensions of learning

Table (1) Test specifications

\begin{tabular}{|l|l|l|l|l|}
\hline Sr & Measured skill & $\begin{array}{l}\text { N. of questions } \\
\text { related to each skill }\end{array}$ & $\begin{array}{l}\text { Sum of the } \\
\text { numbers of } \\
\text { questions }\end{array}$ & Score \\
\hline 1 & Introduce new and unique ideas & $28 \cdot 27 \cdot 11 \cdot 5 \cdot 1$ & 5 & 5 \\
\hline 2 & Suggest solutions to problems & $17 \cdot 14 \cdot 12 \cdot 2$ & 4 & 4 \\
\hline 3 & $\begin{array}{l}\text { Respect for opinion and giving } \\
\text { opinion }\end{array}$ & $18 \cdot 15 \cdot 4$ & 3 & 3 \\
\hline 4 & Set clear goals & $19 \cdot 6 \cdot 29 \cdot 22$ & 4 & 4 \\
\hline 5 & Know the roles & $24 \cdot 21 \cdot 20$ & 3 & 3 \\
\hline 6 & Respect diversity & $23 \cdot 9$ & 2 & 2 \\
\hline 7 & Self-expression & $26 \cdot 8 \cdot 3$ & 3 & 3 \\
\hline 8 & Verbal communication & $25 \cdot 16$ & 2 & 2 \\
\hline 9 & $\begin{array}{l}\text { Discrimination between youth } \\
\text { and differences. }\end{array}$ & $13 \cdot 7$ & 2 & 2 \\
\hline 10 & Negotiation and good inquiry. & $30 \cdot 10$ & 2 & 2 \\
\hline Total & & 35 & 30 & 30 \\
\hline
\end{tabular}

This table could be illustrated by the following graph;

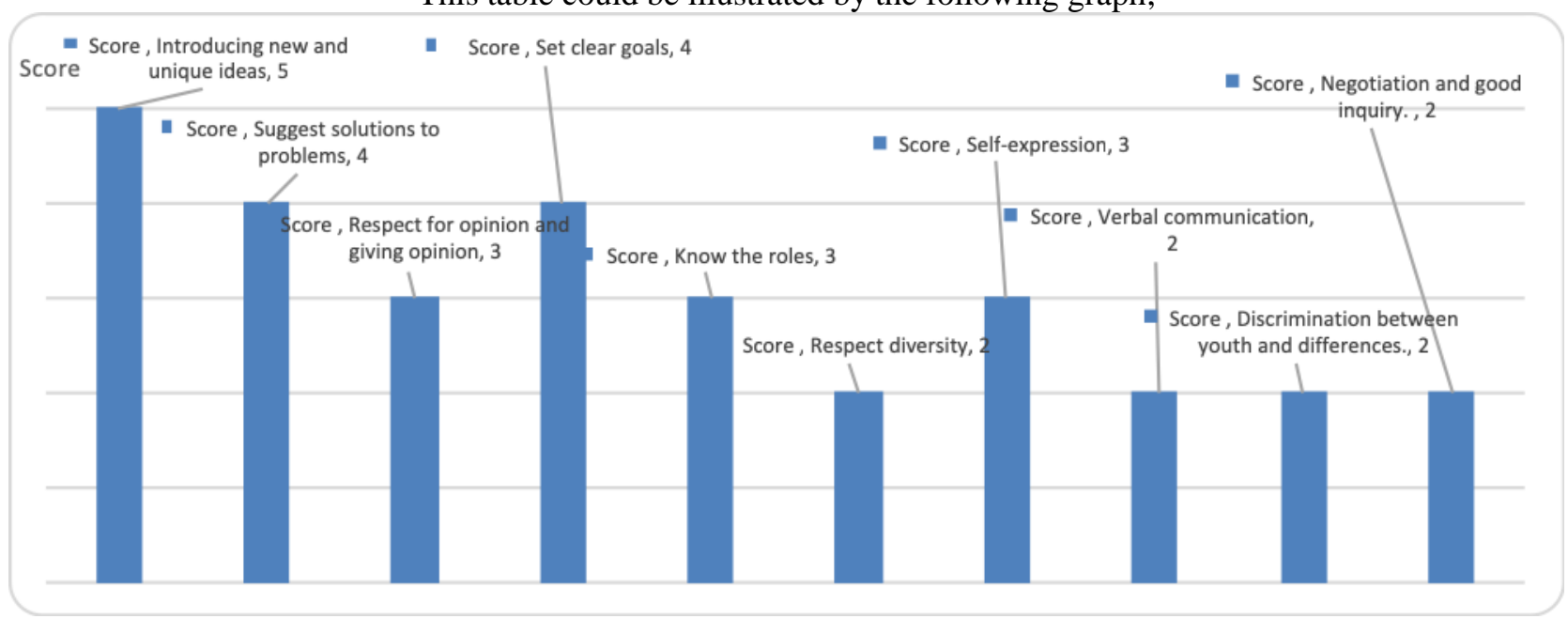

Graph (1): Score given to each measured skill

\subsubsection{Field experimentation of the research:}

The field experimentation was started on Saturday 6/10/2018 and ended on Wednesday 31/10/2018. The experiment was carried out according to procedures that included the following:

3.1.1 Choose a sample search

3.1.2 Experimental Design for Research

3.1.3 Application of learning dimensions test

3.1.4 Training for the research group

3.1.5 Application of the dimensions of distance learning

These procedures are detailed below .

The research sample was selected from the third-grade pupils in 2018/2019 and reached (43) students and students, which were organized through the program's procedures (40) students and students

\section{Study Results and analysis}

\subsubsection{Tribal application of the test}

The learning dimensions test was applied prior to the program training on Sunday and Monday 2-3/9/2018, and grades were maintained. After completing the application of the research tool, the researcher began to apply the program to the research sample according to a specific time plan, and it took 15 hours for 5 weeks 


\subsubsection{Post-test application}

The application was carried out to test the dimensions of learning on the sample after the implementation of the program on Tuesday and Wednesday 6-7 / 4/2018.

Search Results "Discussed and Interpreted".

First Hypothesis: "There are statistically significant variations in the telemetry between the mean scores of the experimental and control groups in the learning dimensions test for the experimental group".

Table (2): Significance of differences between the experimental and control groups in learning dimensions related to Vision 2030

\begin{tabular}{|l|l|l|l|l|l|l|l|}
\hline \multirow{2}{*}{$\#$} & Learning Skills & \multicolumn{2}{|l|}{ Experimental } & Control Groups & Degree of \\
\cline { 3 - 7 } & Average & standard deviation & Average & $\begin{array}{l}\text { The } \\
\text { standard } \\
\text { deviation }\end{array}$ \\
\hline 1 & Scientific skills & 10.1 & 1.61 & 8.20 & 1.53 & 78 & $* 5.38$ \\
\hline 2 & $\begin{array}{l}\text { Professional } \\
\text { skills }\end{array}$ & 18.3 & 1.47 & 11.5 & 2.94 & 78 & $* 12.7$ \\
\hline 3 & $\begin{array}{l}\text { Coexistence } \\
\text { skills }\end{array}$ & 13.0 & 1.54 & 8.65 & 1.49 & 78 & $* 10.5$ \\
\hline 4 & Self-skills & 9.57 & 1.27 & 7.85 & 1.45 & 78 & $* 5.62$ \\
\hline 5 & Total score & 42.52 & 3.78 & 36.25 & 4.88 & 78 & $* 15.1$ \\
\hline
\end{tabular}

This table could be illustrated by the following graph;

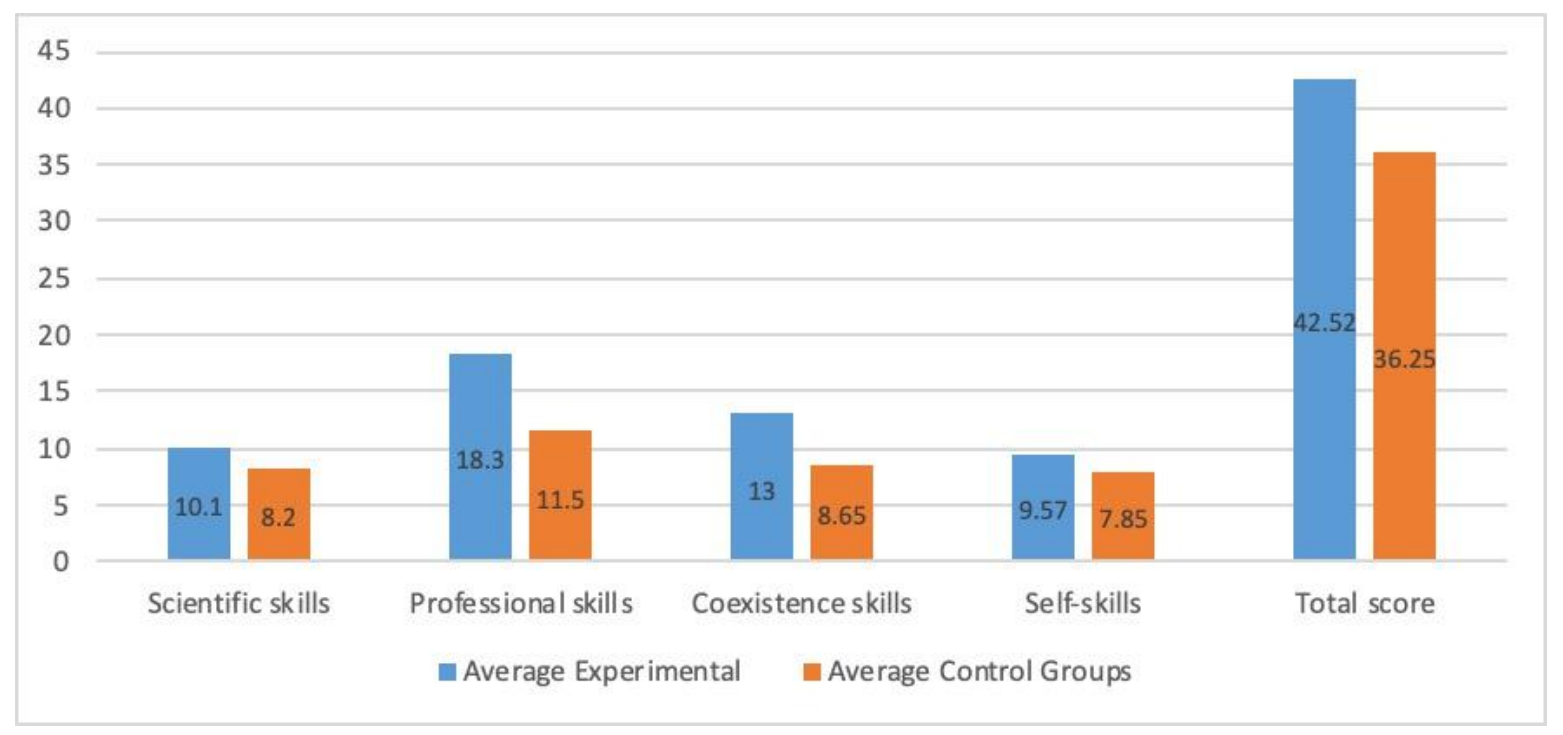

Graph (2): Differences in the average performance between the experimental and control groups in learning dimensions related to Vision 2030

By extrapolating a table (2), there are statistically significant differences at the level of (0.01) between the average performance of students in the experimental and control groups in the dimensions of learning, scientific, professional, coexistence skillsat the primary level .

This is consistent with research on the development of the skills of school media activities (Rania Hussein, 2014; Mr. Ibrahim and Ahmed Darwish, 2011 Mohammed Hussein, 2009 Majedah Abul-Fotouh, 2007; (Livingstone, 2004: 11) that literacy informs students of emerging and contemporary skills and practices of new media users as a reasonable investment of information and communication technologies in their daily lives.

This has given value to the media literacy activities that are practiced in the school in the primary stage, and is consistent with the evolution of the concept of media literacy from the transition from the traditional media literacy in the media to the digital media literacy, which is matched by the literacy of learning from traditional learning within the school to non-traditional learning outside and inside School (Hartley, 2009: 129-130; Scolari, 2018)

Second Hypothesis "There are statistically significant variations in the distance measurement between the intermediate scores of the experimental and control groups in the media literacy test related to the learning dimensions in favor of the experimental group. 
Table (3) Significance of differences between the experimental and control groups in the media literacy test related to learning dimensions

\begin{tabular}{|l|l|l|l|l|l|l|l|}
\hline \multirow{2}{*}{$\mathbf{s r}$} & \multirow{2}{*}{ The Skills } & \multicolumn{2}{|c|}{ Experimental =40 } & \multicolumn{2}{l|}{ Control groups=40 } & Degrees \\
of & Average & $\begin{array}{l}\text { standard } \\
\text { deviation }\end{array}$ & Average & $\begin{array}{l}\text { The } \\
\text { Veviation } \\
\text { Value }\end{array}$ \\
\hline 1 & $\begin{array}{l}\text { Introducing new and unique } \\
\text { ideas }\end{array}$ & 3.32 & 0.91 & 2.67 & 1.07 & 78 & $* 2.19$ \\
\hline 2 & $\begin{array}{l}\text { Suggest solutions to } \\
\text { problems }\end{array}$ & 3.20 & 0.96 & 2.42 & 0.98 & 78 & $* 3.54$ \\
\hline 3 & $\begin{array}{l}\text { Respect for opinion and } \\
\text { opinion }\end{array}$ & 3.57 & 0.67 & 3.10 & 0.77 & 78 & $* 2.91$ \\
\hline 4 & Set clear goals & 3.80 & 0.40 & 2.55 & 1.03 & 78 & $* 7.10$ \\
\hline 5 & Knowledge of roles & 3.62 & 0.66 & 2.50 & 0.90 & 78 & $* 6.32$ \\
\hline 6 & Respect diversity & 3.52 & 0.71 & 2.30 & 0.93 & 78 & $* 6.56$ \\
\hline 7 & Self-expression & 3.67 & 0.72 & 2.15 & 0.80 & 78 & $* 8.89$ \\
\hline 8 & Verbal communication & 3.67 & 0.61 & 2.05 & 0.87 & 78 & $* 9.60$ \\
\hline 9 & Negotiation and good inquiry & 2.50 & 0.78 & 2.17 & 0.74 & 78 & 1.89 \\
\hline 10 & $\begin{array}{l}\text { Distinguish between } \\
\text { similarities and differences }\end{array}$ & 3.55 & 0.78 & 2.55 & $\begin{array}{l}0 \\
87 .\end{array}$ & 78 & $* 5.38$ \\
\hline
\end{tabular}

This table could be illustrated by the following graph;

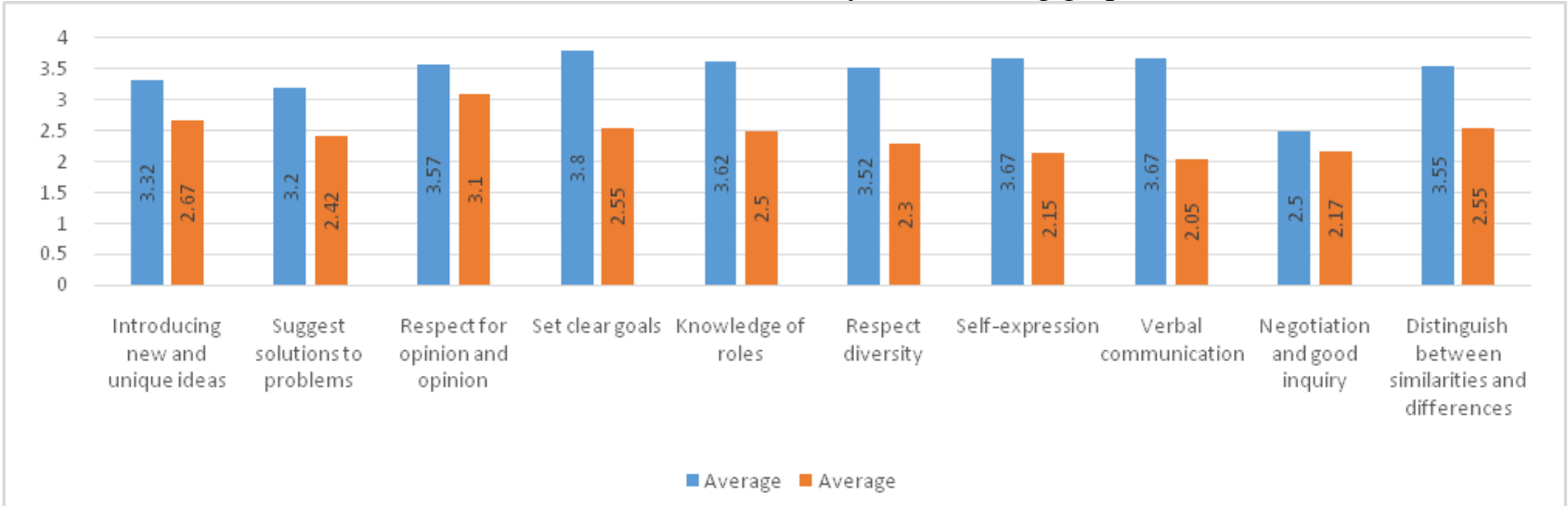

Graph (3): Differences in the average performance between the experimental and control groups in the media literacy test related to learning dimensions

By extrapolating a table (3), there were statistically significant variations at (0.01) between the average performance of the experimental and control groups in the skills of media literacy activities related to the learning dimensions. The value of $\mathrm{T}$ was between $(2.19$ - 10.18) Statistically between the experimental and control groups for the experimental group. This means that students who have been exposed to the program using the skills of media literacy activities related to learning dimensions have achieved greater proficiency in these skills. This can be explained by the following: The program included a set of training activities that influenced the learning skills of the learning group for the experimental group.

This training program provides opportunities for students to explore and discover information and knowledge that can be accessed through the media and through school media practices that make students express themselves and invest or employ school media such as writing a poster, participating in a wall magazine, Academy trains students to propose solutions to problems and respect the other opinion, and respect for cooperative work and verbal communication with others and accept differences with others on the quality and quality of media work, and criticism of current media messages, enabling them to express their interests and express themselves and solve problems related to their lives. And then participate in social and cultural life (Baran \& Davis, 2012; Fraillon et al, 2014)

Therefore, the training of students in the practice of media literacy, communication, work and thinking in a cooperative, creative, responsible and ethical manner is originally a training in the use of digital technology and 
communication tools, and working in teams to produce digital content on topics related to their lives. This training aims to develop the students' scientific research and scientific thinking, to identify the information to be searched for, to identify what might be useful or important to them, to learn to distinguish between the multiple sources of information available, to learn to communicate effectively and to understand how and when to use better digital media techniques.

Thus, the activities of the school media literacy related to the dimensions of learning make the students make extensive conclusions and constitute a set of meaningful relationships between the information they receive through the media and the media as well as employing media sources within the scope of their social environment, which furnishes them with indicators of self-expression, (2016), which makes students have a positive role in activating and activating previous knowledge, new information, and analysis of Las Vegas, Dedication to the new knowledge

This study deals with the effect of the independent variable (media literacy activities) in the dependent variable: (learning dimensions in the light of Egypt 2030 vision). This provides justification for activating the results of this study and disseminating it through the stage. This result is consistent with previous researches and studies, (2007), and the media activities of the school (Hany Ibrahim, 2016; Ragab Mohammed, 2014; Suhail Salem, 2013; Rania Mendo, 2012; Laila Rashad and Alia Yahya, 2009).

Third hypothesis: The program is characterized by an appropriate degree of effectiveness and development to test the skills of the educational activities of the school media related to the dimensions of learning. The results of statistical analyzes were as shown in the following table.

Table (4) (Value2) in measuring the impact of the activities of the school media literacy in the development of learning dimensions in the experimental group (before and after)

\begin{tabular}{|c|c|c|c|c|c|}
\hline$\#$ & Impact dimensions & The Value & $\begin{array}{l}\text { Degrees of } \\
\text { freedom }\end{array}$ & Eta & $\begin{array}{l}\text { Effect } \\
\text { Volume }\end{array}$ \\
\hline 1. & Total score of the test & 15.11 & 78 & 0.75 & Big \\
\hline 2. & Dimensions of learning & & & & \\
\hline a. & Scientific skills & 5.39 & 78 & 0.27 & Big \\
\hline b. & Professional skills & 12.97 & 78 & 0.68 & Big \\
\hline c. & Coexistence skills & 12.88 & 78 & 0.68 & Big \\
\hline d. & Self-skills & 5.62 & 78 & 0.29 & Big \\
\hline 3. & Skills of media literacy act & vities related & education dime & sions $\mathrm{t}$ & \\
\hline a. & $\begin{array}{lll}\begin{array}{l}\text { Introducing } \\
\text { unique ideas }\end{array} & & \text { and } \\
\text { uniquen }\end{array}$ & 2.92 & 78 & 0.10 & Average \\
\hline b. & $\begin{array}{lll}\begin{array}{l}\text { Suggest solutions } \\
\text { problems }\end{array} & \text { to }\end{array}$ & 3.55 & 78 & 0.14 & Big \\
\hline c. & $\begin{array}{l}\text { Respect for opinion and } \\
\text { opinion }\end{array}$ & 2.97 & 78 & 0.10 & Average \\
\hline d. & Set clear goals & 7.10 & 78 & 0.39 & Big \\
\hline e. & Knowledge of roles & 6.32 & 78 & 0.34 & Big \\
\hline f. & Respect for diversity & 6.56 & 78 & 0.36 & Big \\
\hline g. & Self-expression & 8.89 & 78 & 0.50 & Big \\
\hline h. & Verbal communication & 9.60 & 78 & 0.54 & Big \\
\hline i. & $\begin{array}{l}\text { Negotiation and good } \\
\text { inquiry }\end{array}$ & 1.90 & 78 & 0.04 & Small \\
\hline $\mathrm{j}$. & $\begin{array}{lr}\text { Distinguish } & \text { between } \\
\text { similarities } & \text { and } \\
\text { differences. } & \end{array}$ & 5.39 & 78 & 0.27 & Big \\
\hline
\end{tabular}

This table can be expressed in the following figure:

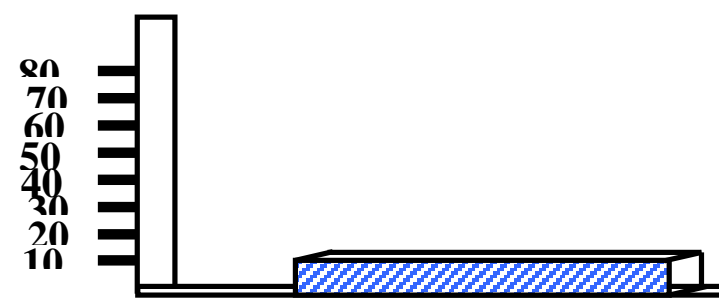

Before

Bevond/After 
To indicate the impact of the measurement of the impact of the activities of the media literacy school on the development of learning dimensions of students before and after the application of the program.

It is clear from the results of Table (4) and the previous graph that the value of the ETA box ( $\eta 2)$ is significant in testing the skills and various dimensions of the activities of the school media, and the total sum of the test of the school media literacy activities, indicating the effectiveness of the proposed program content in developing learning dimensions at Egypt 2030

This can be explained in light of the program as follows:

Active participation among the students of the experimental group and enrich these discussions through the group activities and raise the motivation of students towards the lesson through the use of means and methods of presentation and the use of various activities and stimulate competition among students and open the door to freedom of discussion and opinion .

Adopt the proposed program on mental processes such as conclusion by comparing and extracting similarities or differences. The program provides training in critical thinking skills, introducing new ideas, setting clear goals and specific roles, and organizing educational media activities that contribute to the students' performance of important social and life skills in the school, thus contributing to the achievement of some important learning dimensions in their community, context, and world (Horton, 2007: 15)

The experience of Al-Tanoor Media Program in investigating the relationship between the practices of the media activities and the activities of the literacy activities contributes to some of the higher thinking skills such as critical thinking which contributes to the criticism of the contents of the media messages. This enhances their media awareness and protects them from the negative effects they may be exposed to without proper understanding at this age period . Egyptian space has become available and open to increasingly increasing satellite and radio channels. A growing growth in the written media, whether paper or electronic newspapers, and the widening of the media, including satellite channels, radio stations, newspapers, magazines, electronic forums, the Internet, cinema and theater, posters and advertising

Thus, the value of media literacy activities for the protection and securing of students from media messages, which are mostly uncontrolled and not influenced by social norms or value, but by material profit or ideological guidance, so that messages pass and achieve goals

The media literacy develops students' ability to access, analyze, evaluate, build and practice media strategies that will prevent students from reading the correct media. Here, scholars and researchers stress the importance of critical thinking skills associated with media consumption habits and train students to build content and messages Media education generates informed and informed citizenship and the formation of an independent personality, and enable the practice of the dimensions of modern learning (Fleming 2014, 2015; Mihailidis 2014; Toepfl, 2014)

This is in line with Vraga (Tully, Akin \& Rojas, 2012), which shows that the training of students on media literacy creates an informed personality and is confident of their ability to influence matters and make responsible decisions about their civic and social participation in society. With Ashley, Poepsel \& Willis (2010), learning with media participation has critical thinking skills for the media and has a flexible personality and positive thinking in its school or community environment. It is also consistent with a meta-analysis study (Jeong, Cho \& Hwang, 2012) and shows that media literacy education is often successful and has positive effects on media knowledge, criticism, realism, influence, behavioral beliefs, attitudes, self-efficacy and positive behavior in the position, and in taking responsible decisions

The problem is how to supply the students from childhood a media literacy and protect them from the contents of the media .In fact certain trends may be tendentious at times and aims to create a crisis or negative impact on the recipient. The nature of the media source affects to a certain extent how to formulate and edit the news and how to deal with the events and the lack of awareness of neutrality and objectivity, we find some may be easily affected and criticized in a negative way .

\section{Conclusion and Recommendations}

- Invite media professionals and educators to coordinate between the education sector and the media sector in planning the educational content that can be provided to students.

- Call media institutions to evaluate the information materials that target students periodically in the light of media standards, educational and psychological

- Invite teachers to provide students with behavioral patterns focused on the development of critical thinking and social values that enable them to adapt to changing lifestyles and gain skills that enable them to view the objective examination of things and attitudes. 
- Emphasize the importance of preparing and building plans and programs specialized in media education and in accordance with religious values and national and ethical constants

- Media education is part of the fundamental rights of every citizen in every country in the world. Thus, UNESCO considers the importance of media education because of the influential of media in the modern world.

- At the local level, media education is an effective factor in spreading the culture of dialogue in society and helps the learner to be positive and actively participates in the development, progress and construction of society

- Seize the opportunity in the new media at the level of the world and this is one of the most important aspects of the importance of media education so that we encourage our children to produce media content and dissemination and broadcast in a way that reflects their patriotism, culture and civilization.

\section{Suggested Research}

- A proposed program based on activities and its effectiveness in developing the skills of reading media

- The use of some strategies of media literacy activities to develop journalistic skills

- Proposed program for the development of sustainable development skills in the light of the media

\section{References}

Abdel Wahab Ali Omar (2012): the reality of secondary school in Libya field analytical study, a master's thesis, School of Media and Arts Academy of Graduate Studies, Tripoli, Libya.

Abdul Aziz Mutair Al Anzi (2007): Media Education between Theory and Practice, Okaz Newspaper, p. 2094, Saudi Arabia.

Abdul Rahim Darwish (2007): Issues of Media Education and Modern Trends, published research entitled "Development of Performance in Faculties of Specific Education in Light of Quality and Accreditation Standards", 8th Annual Scientific Conference of the Faculty of Specific Education, Damietta, Mansoura University, April 30-May 1

Abdul Rahman bin Ibrahim Al-Shaer (2007): Media Education: Foundations and Monuments, Naif Arab University for Security Sciences, First Conference of Media Education, Riyadh, Saudi Arabia

Ahmed Abdullah Al-Saghir (2012): Educational Dimensions of the verses of dialogue between parents and children in the Holy Quran, Journal of the Faculty of Education, Assiut University, p3, p.

Ahmed Hussein Hamad (2013): the vision of media professionals and educators to develop media activities (journalism and theater) and the liaison with Libyan schools, Journal of Media Research, p. 39, January, Faculty of Information, Al-Azhar University.

Ahmed Mohamed Osman (2006): the practice of school information activities and its relationship to the creative abilities of students in the preparatory stage, a master's thesis, Institute of Graduate Studies for Children, Ain Shams University

Al-Farhati Mr. Mahmoud (2009): Learned deficit, educational and social issues, the Anglo-Egyptian Library, Cairo

Ashley, Seth, Mark Poepsel\& Erin Willis. (2010) Media Literacy and News Credibility: Does Knowledge of Media Ownership Increase Skepticism in News Consumers?” Journal of Media Literacy Education 2: 37-46.

Asmaa Bakr Al-Siddiq (2014): Conceptualization of the Role of Educational Media Specialist in Preparatory Schools in Light of Modern Concepts of Media Education, Master Thesis, Faculty of Specific Education, Damietta University.

Atef Adly Al-Abd; Adly Reza (2008): Management of Media Institutions, Dar Al-Fikr Al-Arabi, Cairo

Avery, R. K., (2007). The Public Broadcasting Act of 1967: Looking ahead by looking back. Critical Studies in Mass Communication, 24(4), 358-364.

Baran, S.\& Davis, D.(2012). Mass Communication Theory: Foundations, Fervent and Future. (Sixth Ed). Wadsworth: Cengage Learning.

Brunner, C. B. \& Tally, W. (1999). The new media literacy handbook: An educator's guide to bringing new media into the classroom. New York: Anchor Books.

Buckingham, D. (2003) Media Education: Literacy, Learning and Contemporary Culture Cambridge: Polity

Dr. Daria Al-Banna (2004) "The Reality of Free Educational Activities in Secondary Azhar Institutes", Journal of the Faculty of Education, Zagazig University, Issue 47, May

Eman Ahmed Khader (2011): Recent trends in the development of the academic performance of the program of preparing the specialist of theatrical education assessment study, Journal of Specific Education Research, p. 19, January, Faculty of Specific Education, Mansoura University.

Essam Tawfiq Qamar (2008): Integration between the educational process and school activities in the primary school, the modern university office, Cairo. 
Fahmi Tawfiq Mohammed (2012): School activity, its concept and organization and its relation to the curriculum, Dar Knouz Knowledge, Amman.

Fayza Bint Mohammed Al-Akhdar (2007): The exposure of teachers to the media and its implications for the emerging (analytical descriptive study), the first international conference on media education, paper presented at the conference 4-7 / 3/2007.

Ferrés J., Piscitelli A., (2012) "La competencia mediática: propuesta articulada de dimensiones e indicadores" (The media competition: articulated proposal of dimensions and indicators - original source in Spanish], Comunicar, 19 (38), pp.75-82.

Fleming, J ( 2015) "What do Facts Have to do with it? Exploring Instructional Emphasis in Stony Brook News Literacy Curriculum." Journal of Media Literacy Education 7: 73-92.

Fleming, J (2014) "Media Literacy, News Literacy, or News Appreciation? A Case Study of the News Literacy Program at Stony Brook University." Journalism and Mass Communication Educator 69: 146-165.

Fraillon J., Ainley J., Wolfram S., Friedman T\& Gebhardt E., (2014). Preparing for life in a digital Age. The IEA International Computer Literacy Study. International Report. Springer Open.

Friesem, Y. (2013). "Review: Media Literacy in the K-12 Classroom (2012)." Journal of Media Literacy Education 5 (2). 395-396 Fry, K.G. (2015) "Developing Media Literacy: Managing Fear and Moving Beyond," Journal of Media Literacy Education 6 (3): 65-70.

General plan for the activities of the school press, General Directorate of Cultural and Artistic Activities, Department of School Press, Ministry of Education, 2015/2016.

Goodman, S (2003). Teaching Youth Media. A critical guide to literacy, video production, and social change. New York: Teachers College Press

Grant, I. (2004) Young people's relationships with digital media: the good, the bad, and the (occasionally) ugly Paper presented at Digital Generations conference, Institute of Education, London

Hartley, J (2009). "Uses of YouTube. Digital literacy and the growth of knowledge". In: Burgess, Jean; Green, Joshua (eds.), YouTube: Online video and participatory culture. Cambridge, UK: Polity, pp. 126-143. ISBN: 9780 745644790

Hobbs, R., \& Moore, D. C. (2013). Discovering media literacy: Teaching digital media and popular culture in elementary school. Thousand Oaks, CA: Corwin.

Horton, F. W. (2007). Understanding information literacy: A primer. Paris, France: Information Society Division, Communication and Information, UNESCO.

Ismail, Mahmoud Hassan (2011): Media and Child Culture, 1, Arab Thought House, Cairo.

Jenkins, H. (2008). Editorial. Convergence, 14(1), 5-9.

Jeong, Se-Hoon, Hyunyi , C, \& Yoori H (2012) Media Literacy Interventions: A Meta-Analytic Review." Journal of Communication 62: 454-472.

Lid Kamal Al-Kafas and Esam Tawfiq Qamar (2002), "The Effect of Educational Activities on Self-Esteem and Aggression", Journal of Educational Research, Volume I, No. 1, Cairo: National Center for Educational Research and Development, January

Lili Rashad and Alia Yahia (2009): The Concept of Media Education in the Books of Civic Education and National Education for the Basic Stage in the Palestinian Curriculum, Presented at the "Educational Process in the 21st Century: Challenges and Challenges", An-Najah National University, 17-18 October

Livingstone, S (2004). "Media literacy and the challenge of new information and communication technologies". The communication review, v. 7, n. 1, pp. 3-14.

Livingstone, S. \& Bober, M. (2004) Active participation or just more information? Young people's take up of opportunities to act and interact on the Internet London: London School of Economics and Political Science

Livingstone, S. \& Bovill, M. (1999) Young People, New Media London: London School of Economics and Political Science

Livingstone, S. (2008). Taking risky opportunities in youthful content creation: Teenagers' use of social networking sites for intimacy, privacy and self-expression. New Media \& Society, 10(3), 393-411

Luckin, R. (2008). The learner centric ecology of resources: A framework for using technology to scaffold learning. Computers and Education, 50, 449-462.

Lundby, K. (2009). Mediatization as key. In K. Lundby (Ed.), Mediatization: Concept, Changes, Consequences. New York: Peter Lang.

Magda Abul-Fotouh Al-Hariri (2007): Values included in the children's programs in the Nile channel for family and children, analytical study, master's thesis, Institute of Graduate Studies for Children, Ain Shams University

Magda Lotfi Al-Sayed (2011): Educational and Educational Media Technologies, 1, Dar Osama Publishing and Distribution, Jordan-Amman 
Maha Abdel-Fattah Abou Elmagd (2012): A Proposed Concept for Media Education in Secondary Education Schools in the Arab Republic of Egypt in Light of Some International Experiences, Master Thesis, Faculty of Education, Aswan University.

Maha Salah Eddin Mohammed (2005): Contributions of Educational Activities in Kindergartens, Future of Arab Education, p 37, Faculty of Education, Ain Shams University

Meeus, W., J. Van Ouytsel, A. Driesen, \& Sas , J (2014) Media Literacy in the Digital Age. How to Benefit from Media Use while Protecting against Harm. The Journal of Didactics 5 (1\&2): 64-79.

Meyrowitz, Joshua. (1985) No Sense of Place: The Impact of Electronic Media on Social Behaviour. New York: Oxford University Press

Mihailidis, P.(2014). Media Literacy and the Emerging Citizen: Youth, Engagement and Participation in Digital Culture. New York: Peter Lang.

Ministry of Education (2003), National Standards for Education in Egypt - National Standards Preparation Project, Volume I, (Cairo: Hope for Printing and Publishing, p. 168).

Ministry of Education (2011): Teacher's Guide in the Comprehensive Assessment of the Basic Education Stage in its Primary and Preparatory Courses.

Mohamed Attia Abu Fouda (2006): The Role of Educational Media in Strengthening National Belonging among University Students in Gaza Governorates, MA Thesis,

Mohamed Ibrahim Al-Ruwaini (2012): Professional competencies required to develop the performance of the school theater specialist in the preparatory stage schools, PhD thesis, Faculty of Specific Education, Mansoura University.

Mohammed Al-Khatib (2007): The Role of the School in Media Education, The First International Conference on Media Education, Ministry of Education and UNESCO, Riyadh, Saudi Arabia.

Mohammed, Ahmed Hussein (2009): Problems of the contact in the activities of the school media and its relationship to job satisfaction and student benefit, a survey on the province of Dakahlia, $\mathrm{PhD}$ thesis, Institute of Graduate Studies for Children, Ain Shams University

Mr. Ibrahim and Ahmed Darwish (2011): Effectiveness of a training program in the school press to develop the creative ability and awareness of journalists in the preparatory stage students, Master Thesis, Faculty of Specific Education, Mansoura University

Mueller J., Wood E., Willoughby T., Ross C., Specht, J., (2008) "Identifying discriminating variables between teachers who fully integrate computers and teachers with limited integration", Computers \& Education, 4(51), pp.15231537.

National Association for Media Literacy Education. (2007). Core principles of media literacy education in the United States. $\quad$ Retrieved October 31, 2009, from http://namle.net/uploads/r4/cE/r4cEZukacxNYaFFxlMONdQ/NAMLE-CPMLE-wquestions.pdf

Neag, A.(2015)."Media Literacy and the Hungarian National Core Curriculum - A Curate's Egg," Journal of Media Literacy Education 7 (1): 35 -45.

Potter, W. J. December, 2010. The State of Media Literacy. Journal of Broadcasting and Electronic Media. (54: 4 p. 675-696). Retrieved on 15 August, 2014 from http://mysite.disu.edu.ph/faculty/marianog/publish/potter.pdf

Rajab Mohamed Gouda (2014): Activating the Educational Role of School Press Specialists in the Arab Republic of Egypt in Light of the Experience of Some Countries, Comparative Study, Master Thesis, Faculty of Education, Banha University.

Rania Abdel-Azim Hussein (2014): Role of Media Activities in the Association of Integrated Care in Raising Awareness of the Values of Citizenship in Egyptian Children from 9-12 years, Master Thesis, Institute of Graduate Studies for Children, Ain Shams University

Rania Mendoo Galal (2012): The means of communication in institutions and NGOs and their relationship to the attitudes of adolescents towards the values of civil society, Institute of Graduate Studies for Children, Ain Shams University

Rodriguez-Rossel, m \& Moreno , m , I (2016): The dimensions and indicators of media literacy in the first stages of schooling, ATI - Applied Technologies and Innovations Volume 12 | Issue 2 | 2016 |pp.69-79

Said Hanafi Hussein (2009): Values of citizenship included in some children's stories, Master, Institute of Graduate Studies for Children, Cairo, Ain Shams University

Samia Abdel Hakim Ahmed (2010): A Proposed Approach in Media Education under National Standards for Total Quality, Master Thesis, Faculty of Education.

Scheibe, C., \& Rogow, F. (2012).The teacher's guide to media literacy: Critical thinking in a multimedia world. Thousand Oaks, CA: Corwin 
Scolari, C (2018). Teens, media and collaborative cultures: exploiting teens' transmedia skills in the classroom. Barcelona: Transmedia Literacy H2020 Research and Innovation Action / Universitat Pompeu Fabra. ISBN: 978846979843

Silverblatt, A. (2001). Media Literacy: Keys to interpreting media messages. Westport, CT

Silverstone, R. (2004). Regulation, Media Literacy and Media Civics. Media, Culture and Society. 26 (3), 440-449.

Suhail Salem (2013): Media and Educational Communication in the pre-university education stages in the Arabian Gulf between the local and international, Sultanate of Oman model, $\mathrm{PhD}$ thesis, Institute of Journalism and News Science, Manouba University, Tunisia.

Tarek Mohammed Mohamed (2005): The role of educational media in developing media awareness among students in the preparatory stage. A proposed curriculum, $\mathrm{PhD}$ thesis, Institute of Graduate Studies for Children, Ain Shams University.

Toepfl, F. (2014). "Four Facets of Critical News Literacy in a Non- Democratic Regime: How Young Russians Navigate their News." European Journal of Communication 29: 69-82.

UNESCO, (2008.) ICT Competency framework for teachers.

UNESCO, (2011). Media and Information Literacy, Curriculum for Teachers.

Vraga, Emily K., Melissa Tully, Heather Akin,\&Hernando R (2012). "Modifying Perceptions of Hostility and Credibility of News Coverage of an Environmental Controversy through Media iteracy." Journalism 13: 942959.

Waleed Abdel Fattah, Duaa Fathy (2009): Trends of Media Teaching Staff and Their Assistants in Egyptian Universities Towards the Application of Quality and Accreditation Standards, Field Study, Journal of Childhood Studies, Issue 45, Sun

Zaid Zayed Al-Harithi (2008): The contribution of educational media to the achievement of intellectual security among high school students in Makkah city from the point of view of principals of school agents and educational supervisors, Master Thesis, Faculty of Education, Umm Al-Qura University, Saudi Arabia.

80. Zhang, H. \& Zhu, C. (2014). A review of media literacy education: How is it integrate into curriculum? Accessed on 2 September, 2014 from http://www.eera-ecer.de/ecer-programmes/conference/6/contribution/16669/ 